\title{
Preemptive use of Small Dose Fentanyl Suppresses Fentanyl Induced Cough
}

\author{
Shrestha SK, Bhattarai B, Shah RS
}

Department of Anesthesia

Kathmandu University School of Medical Science

Dhulikhel Hospital, Kathmandu University Hospital

Dhulikhel Kavre, Nepal

\section{Corresponding author}

Santosh Kumar Shrestha

Department of Anesthesia

Kathmandu University School of Medical Science

Dhulikhel Hospital, Kathmandu University

Dhulikhel Kavre, Nepal

Email: drsantosh_shrestha@yahoo.com

\section{Citation}

Shrestha SK, Bhattarai B, Shah RS. Preemptive use of Small Dose Fentanyl Suppresses Fentanyl Induced Cough. Kathmandu Univ Med J 2012;10(4):16-19.

\section{ABSTRACT \\ Background}

Fentanyl, a synthetic opioid, is a popular choice amongst anaesthesiologists in the operating room. Pre induction intravenous fentanyl bolus is associated with coughing in $28-65 \%$ of patients. Fentanyl induced cough is not always benign and can be remarkably troublesome at the most critical moment of anaesthesia when airway reflex is lost.

\section{Objectives}

To study the effect of pre emptive use of minimal dose fentanyl through the peripheral venous cannulae on the incidence of cough by a larger bolus of intravenous fentanyl.

\section{Methods}

One hundred and fifty patients aged 18 -75 years undergoing elective surgical procedures were randomized into three groups of 50 each. The first group received $0.5 \mathrm{ml}$ saline $0.9 \%$ intravenously one minute prior to the administration of fentanyl $150 \mu \mathrm{g}(3 \mathrm{ml})$; the second group received pre emptive fentanyl $25 \mu \mathrm{g}(0.5 \mathrm{ml})$ prior to the administration of fentanyl $125 \mu \mathrm{g}(2.5 \mathrm{ml})$; and the third group received preemptive fentanyl $25 \mu \mathrm{g}(0.5 \mathrm{ml})$, followed by the administration of fentanyl $150 \mu \mathrm{g}(3 \mathrm{ml}) .$. Based on the number of coughs observed, cough severity was graded as mild(1-2), moderate (3-5), or severe (>5).

\section{Results}

The incidence of fentanyl induced cough was significantly lower in both pre emptive group $4(8 \%)$ for $125 \mu \mathrm{g}$ fentanyl and $7(14 \%)$ for $150 \mu \mathrm{g}$ than in the saline group $15(30 \%)$.

\section{Conclusion}

Pre- emptive use of minimal dose fentanyl $25 \mu \mathrm{g}$ administered one minute before a larger bolus dose of fentanyl (125 or $150 \mu \mathrm{g}$ ) can effectively suppress cough.

\section{KEY WORDS}

Cough, fentanyl, pre emptive 


\section{INTRODUCTION}

Opioids are used to decrease pain and allay anxiety associated with surgery. Fentanyl, a synthetic opioid, is widely used during general anesthetic induction because of its quick onset, short duration of action, intense analgesia, cardiovascular stability, and no histamine release. ${ }^{1,2}$ Reflex cough is often observed after an iv bolus of fentanyl during induction, frequency ranging from 28 $-65 \% .^{3-8}$ Some authors have reported a case of explosive coughing after intravenous (IV) fentanyl that produced multiple conjunctival and periorbital petechiae. ${ }^{9}$ Fentanyl induced cough is not always benign and is undesirable in patients with some pre-existing disease, including cerebral aneurysm, brain trauma, open eye injury, dissecting aortic aneurysm, pneumothorax, and reactive airway disease. ${ }^{6,8,9}$

Various interventions has been tried to reduce the incidence of fentanyl induced cough by using anaesthetic adjuncts and other maneuver. These include $\beta 2$ receptor agonist, epheridine, lidocaine ketamine, clonidine, dexamethasone, dexmedetomidine, a huffing manoeuvre prior to induction etc. ${ }^{5-8,10-14}$ All these approaches which are tried are not uniformly effective.

$\mathrm{Yu}$ et al found that prolonged injection time of fentanyl may reduce the incidence of coughing. ${ }^{15}$ This slow injection time reduces peak drug concentration, suggesting that fluctuations in plasma fentanyl concentrations may have contributed to coughing. This led us to hypothesize that pre-emptive use of small dose fentanyl prior to the subsequent larger dose may prevent coughing.

\section{METHODS}

After obtaining approval from the institutional ethical committee of the hospital and informed consents from the patients, 150 adults patients of American society of anesthesiologist physical status I or II, aged 18- 75 years and scheduled for elective surgery during general anesthesia were enrolled in this randomized, prospective double blind placebo control study. The study was conducted at Dhulikhel hospital, Kathmandu university hospital, between January 2012 and June 2012.

Exclusion criteria included history of asthma, chronic cough, upper respiratory tract infection in the previous two weeks, a history of bronchodilator or steroid therapy, or medication with angiotensin converting enzyme inhibitor. The smoking status of all patients was assessed, as smoking has been reported to suppress fentanyl induced cough. ${ }^{16,17}$

All patients were pre medicated with oral lorazepam $0.04 \mathrm{mg} / \mathrm{kg}$ and pantoprazole $40 \mathrm{mg}$ the night before and morning of surgery. Before induction of anesthesia, venous access was established with 20gauge cannula on the dorsum of the hand. All patients were monitored by electrocardiogram, non invasive blood pressure, pulse oximetry, end tidal carbon dioxide and temperature.
Patients were randomly assigned into three groups:

Group 1: Received $0.5 \mathrm{ml}$ normal saline intravenously 1 min prior to the administration of fentanyl 150 $\mathrm{g}$ ( $3 \mathrm{ml}$ )

Group 2: Received pre emptive fentanyl $25 \mu \mathrm{g}(0.5 \mathrm{ml})$ prior to the administration of fentanyl $125 \mu \mathrm{g}(2.5 \mathrm{ml})$;

Group 3: Received preemptive fentanyl $25 \mu \mathrm{g}(0.5 \mathrm{ml})$, followed by the administration of fentanyl $150 \mu \mathrm{g}(3 \mathrm{ml})$.

General anesthesia was induced after the cessation of cough if cough occured or $1 \mathrm{~min}$ after the end of bolus injection. If desaturation was noted, assisted mask ventilation with oxygen was applied.

A blind observer recorded the number of coughs that occurred after the fentanyl was administered within first minute. Based on the number of coughs observed, cough severity was graded as mild (1-2), moderate (3-5), or severe $(>5)$. Non invasive blood pressure (systolic blood pressure, diastolic blood pressure,) and heart rate were recorded one minute prior and one minute after fentanyl administration.

All data are reported as mean \pm SD or number (proportion). One way ANOVA was used to compare the means of continuous data of all three groups. The relative magnitude of the associations between groups and the likelihood of fentanyl induced cough were compared by calculating adjusted odds ratio (OR). The precision of the estimated OR was assessed by the use of $95 \%$ confidence interval( $\mathrm{Cl})$. Statistical analyses were performed using statistical package for social sciences ( SPSS) version 17.

\section{RESULTS}

The groups were similar in demographic characteristics, ASA physical status as well as smoking status.(table 1$)$. Group 2 patients coughed less than Group 1 patients ( OR $=0.197 ; 95 \% \mathrm{Cl} 0.60-0.647)$, as did the patients in group 3 (OR = 0.369; $\mathrm{Cl} 0.135-1.007)$ (table 2). Severe cough was not observed in either pre emptive group (table 3).There was no significant difference in the the haemodynamic variable among the three groups before or after fentanyl administration (table 4).

Table 1. Demographic Profile of different group of patients prior to induction. Values are mean(SD) or number (proportion).

\begin{tabular}{|llll|} 
& Group I & Group II & Group III \\
\hline Age(Years) & $42.22(14.10)$ & $40.24(13.45)$ & $39.88(14.99)$ \\
\hline Sex:M/F & $16 / 34$ & $17 / 33$ & $14 / 36$ \\
\hline Weight:Kg & $56.22(6.2)$ & $57.96(8.13)$ & $55.80(5.42)$ \\
\hline ASA I & $35(70 \%)$ & $41(82 \%)$ & $40(80 \%)$ \\
\hline ASA II & $15(30 \%)$ & $9(18 \%)$ & $10(20 \%)$ \\
\hline Smoker & $12(24 \%)$ & $11(22 \%)$ & $14(28 \%)$ \\
\hline Nonsmoker & $38(76 \%)$ & $39(78 \%)$ & $36(72 \%)$ \\
\hline
\end{tabular}


Table 2. Incidence of cough in Group I group II and Group III patients. Values are number (proportion) or ( $95 \% \mathrm{Cl})$.

$\begin{array}{llll} & \text { Group I } & \text { Group II } & \text { Group III } \\ \text { Incidence of cough } & 15(30 \%) & 4(8 \%) & 7(14 \%) \\ \text { Odds ratio } & 1 & 0.197(0.60- & 0.369(0.135- \\ & & .647)^{*} & 1.007)^{*}\end{array}$

$\mathrm{p}<0.05$ compared with saline fentanyl group (Both are significantly associated)

Table 3. Severity of cough in Group I, Group II Group III patients. Values are number (proportion).

\begin{tabular}{llll} 
& Group I & Group II & Group III \\
\hline Mild & $7(46.7)$ & $3(75)$ & $4(57.14)$ \\
\hline Moderate & $5(33.3)$ & $1(25)$ & $3(42.86)$ \\
Severe & $3(20)$ & 0 & 0
\end{tabular}

Table 4. Haemodynamic variable $1 \mathrm{~min}$ prior and $1 \mathrm{~min}$ after injection in Group I group II and Group III. Values are mean(SD).

\begin{tabular}{|c|c|c|c|c|c|}
\hline & Group I & Group II & Group III & $\begin{array}{l}p \text { Val- } \\
\text { ue }\end{array}$ & \\
\hline $\begin{array}{l}\text { HR pre per/ } \\
\text { min }\end{array}$ & $77.24(7.07)$ & $76.14(5.03)$ & $74.88(5.43)$ & 0.265 & NS \\
\hline $\begin{array}{l}\text { HR post } \\
\text { per/min }\end{array}$ & $74.72(5.85)$ & $73.92(5.15)$ & $73.50(6.54)$ & 0.181 & NS \\
\hline $\begin{array}{l}\text { SBP } \\
\text { pre:mm Hg }\end{array}$ & $\begin{array}{l}121.16(6 . \\
68)\end{array}$ & $\begin{array}{l}120.32(5 . \\
78)\end{array}$ & $121.34(5.8)$ & 0.317 & NS \\
\hline $\begin{array}{l}\text { SBP } \\
\text { post;mmHg }\end{array}$ & $\begin{array}{l}116.52(9 . \\
26)\end{array}$ & $\begin{array}{l}117.34(6 . \\
93)\end{array}$ & $\begin{array}{l}117.58(7 . \\
47)\end{array}$ & 0.479 & NS \\
\hline $\begin{array}{l}\text { DBP } \\
\text { pre:mmHg }\end{array}$ & $76.54(4.96)$ & $74.26(7.16)$ & $77.42(6.07)$ & 0.333 & NS \\
\hline $\begin{array}{l}\text { DBP } \\
\text { post:mmHg }\end{array}$ & $73.28(5.07)$ & $72.50(6.85)$ & $74.82(5.36)$ & 0.027 & NS \\
\hline
\end{tabular}

\section{DISCUSSION}

This study demonstrated that the incidence of fentanyl induced cough could be reduced with pre emptive administration of fentanyl $25 \mu \mathrm{g}$ prior to the larger bolus dose $125 \mu \mathrm{g}$ or $150 \mu \mathrm{g}$ during the induction of anesthesia.

The incidence of cough in the group that didn't receive the pre emptive dose of fentanyl was $30 \%$ which is similar to the previous study where the reported incidence of cough following an intravenous bolus of fentanyl was 28 $-65 \% .^{3-7}$ Fentanyl induced cough is commonly observed during induction of anaesthesia. In the study by Bohrer et al $45.9 \%$ of the patients coughed after receiving $7 \mu \mathrm{g} / \mathrm{kg}$ fentanyl through a central venous catheter. ${ }^{3}$ Another study by Lui et al, $43 \%$ of patients coughed after receiving $5 \mu \mathrm{g} /$ $\mathrm{kg}$ of fentanyl injected through a peripheral venous line. ${ }^{5}$ Phue et al found that fentanyl $1.5 \mu \mathrm{g} / \mathrm{kg}$ given through a peripheral venous line elicited cough in $28 \%$ of the patients and a similar incidence of cough was observed by Agarwal et al following $2 \mu \mathrm{g} / \mathrm{kg}$ given through peripheral venous line over a period of five seconds. ${ }^{4,6}$ The discrepancy in the incidence of cough among these studies can be explained by the differences in injection dose, route of administration and period of injection.
Lin et al found that there was an age related incidence of fentanyl induced cough. ${ }^{7}$ Another study by Lin et al. showed that longer injection time reduces the incidence of fentanyl induced cough, and light smoking may be a protective factor against fentanyl cough. ${ }^{16}$ Another study by Jung et al showed that priming dose of fentanyl didn't reduce the incidence and severity of fentanyl induced cough and former smokers were found to cough more than current smokers after injection of fentanyl. ${ }^{18}$ Contradictory to their studies we didn't find any association between age and smoking status on the incidence of cough in any of the groups. This may be due to the wide age range of the patients studied (18- 75 years).

Lin et al showed that the threshold for fentanyl induced cough may be reached more easily at a larger peak plasma concentration; therefore, longer the injection time, less frequent is fentanyl induced cough. ${ }^{16}$ The low incidence of fentanyl induced cough in our study may be explained by this pharmacokinetic view that the duration of drug injection may affect the peak plasma concentration. Fentanyl induced cough has been reported to occur within 15-20 sec after administration of intravenous fentanyl so we decided to administer the preemptive fentanyl one min before the larger dose of fentanyl, to ensure that the preemptive dose had completed one arm brain circulation time. ${ }^{17}$

The mechanisms of fentanyl induced cough are not well understood but various theories have been proposed. Fentanyl has been shown to inhibit central sympathetic outflow causing vagal predominance, which inturn causes cough and reflex bronchoconstriction. ${ }^{5,6,19}$ Effective suppression of the cough response from $43 \%$ to $3 \%$ after terbutaline and salbutamol (selective $\beta 2$ Agonist) inhalation supports the concept of bronchoconstriction. ${ }^{5}$ The rapid response of the reflex and efficacy of morphine in preventing cough suggests that a pulmonany chemoreflex is also the likely mechanism, mediated by either irritant receptor or by Vagal C fiber receptors in close proximity to pulmonary vessels (juxta capillary receptors). Suppression of cough with betamethasone inhalation supports the trigger stimulus and bronchial hyperirritability theory. ${ }^{5,6,9}$ Inhibition of cough response from $21.6 \%$ to $7.2 \%$ after ketamine pretreatment suggest that NMDA receptor has been demonstrated in larynx, lung, and airways, and activation of these receptors can trigger airway constriction. ${ }^{10}$ Fentanyl induced muscle rigidity is another important causal factor. The $\alpha 2$ adrenoreceptor agonists ability to reverse opioid induced muscular rigidity has been demonstrated in rats. ${ }^{20}$ It is possible that $\alpha 2$ adrenoreceptor agonist reduce the incidence of fentanyl induced cough via reversal of fentanyl induced muscular rigidity and not through sedation. ${ }^{21}$

Many physical methods and drugs havebeen reported to prevent fentanyl induced cough, including ephedrine, lidocaine, and propofol. ${ }^{7,8,22}$ A huffing maneuver was reported as a useful way to prevent fentanyl induced 
cough, but some patients who receive midazolam or propofol during induction of general anesthesia cannot use this maneuver. ${ }^{14}$

Although the above mentioned medications could reduce the incidence of coughing, some unexpected side effects may occur during drug administration, such as malignant arrhythmia, hypotension, and hypertension. Pretreatment with lidocaine can augment the cardiovascular depression of induction agents. ${ }^{23}$ Intravenous ephedrine before fentanyl injection can be contraindicated in patients with coronary artery disease or moderate to severe hypertension. ${ }^{14}$ Using high doses of propofol can be associated with high incidence of hypotension. ${ }^{22}$ Pretreatment with clonidine is associated with respiratory depression, drowsiness, and severe hypotension. ${ }^{11}$

All these drugs and maneuver which have been tried to attenuate the fentanyl induced cough may not only be more costly but it may also be unnecessary. So this study is intended and will help to avoid the use of multiple drugs to attenuate fentanyl induced cough.

A limitation of this study was that a dose response experiment was not performed to determine the optimal

\section{REFERENCES}

1. Bovill JG, Sebel PS, Stanley TH. Opioid analgesics in anesthesia: with special reference to their use in cardiovascular anesthesia. Anesthesiology 1984;61:731-55.

2. Grell FL, Koons RA, Denson JS. Fentanyl in anesthesia: a report of 500 cases. Anesth Analg 1970;49:523-32.

3. Bohrer, Fleischer F, Werning P. Tussive effect of a fentanyl bolus administered through a central venous catheter. Anaesthesia 1990;45:18-21.

4. Phua WT, Teh BT, Jong W, Lee TL, Tweed WA. Tussive effect of a fentanyl bolus. Can J Anaesth 1991;38:330-4.

5. Lui PW, Hsing $\mathrm{CH}$, Chu YC. Terbutaline inhalation suppresses fentanyl induced coughing. Can J Anaesth 1996;43: 1216-9.

6. Agarwal A, Azim A, Amesh S. Salbutamol, beclomethasone or sodium chromoglycate suppress coughing induced by IV fentanyl. Can J Anaesth 2003;50:297-300.

7. Lin CS, Sun WZ, Chan WH, Lin CJ, Yeh HM, Mok MS. Intravenous lidocaine and ephedrine, but not propofol, suppress fentanyl-induced cough. Can J Anaesth 2004;51:654-9.

8. Pandey CK, Raza M, Ranjan R. Intravenous lidocaine suppresses fentanyl induced cough: a double blind, prospective, randomized placebo- controlled study. Anesth Analg 2004;99:1696-8.

9. Tweed WA, Dakin D. Explosive coughing after bolus fentanyl injection. Anesth Analg 2001;92:1442-3.

10. Yeh CC, Wu CT, Huh BK. Premedication with intravenous low dose ketamine suppresses fentanyl induced cough. Journal of Clinical Anaesthesia 2007;19:53-6.

11. Horng HC, Wong CS, Hsiao KN. Premedication with intravenous clonidine suppresses fentanyl induced cough. Acta Anaesthesiol Scand 2007; 51:862-865.

12. Lin JA, Chen FC, Lee MS. Intravenous dexamethasone pretreatment reduces fentanyl induced cough. J Formos Med Assoc 2007;106:649655. dose of fentanyl that can reduce the cough prior to the larger bolus dose. Although we choose $25 \mu \mathrm{g}$ fentanyl as a pre emptive dose we don't know this dose is effective in attenuating cough response elicited by fentanyl at any larger dose. Further studies are warranted to determine the optimum dose of fentanyl that will suppress fentanyl induced cough.

\section{CONCLUSION}

Our study suggests that pre emptive use of minimal dose fentanyl $25 \mu \mathrm{g}$ administered $1 \mathrm{~min}$ prior to the larger bolus dose of fentanyl $(125 \mu \mathrm{g}$ or $150 \mu \mathrm{g}$ ) can effectively suppress cough and is a simple and cost effective method to prevent fentanyl induced coughing.

\section{ACKNOWLEDGEMENT}

We would like to thank Mr Roshan Mahato, Department of Community Medicine for his assistance in statistical analysis.

13. Liang $H E$, Jun - Xu, Ru Dai. Dexmedetomidine reduces the incidence of fentanyl induced cough: A double blind, randomized, placebo controlled study. Upsala Journal of Medical sciences 2012;117:18-21.

14. SP Ambesh, N Singh, D Gupta. A huffing manoeuvre, immediately before induction of anaesthesia, prevents fentanyl induced coughing: a prospective, randomized, and controlled study. $\mathrm{Br} J$ Anaesth 2010;104:40-3.

15. $H$. Yu, X Yang, $X$ Zhang. The effect of dilution and prolonged injection time on fentanyl induced coughing. Anaesthesia 2007;62:919-22.

16. Lin JA, Yeh CC, Wu CT. Prolonged injection time and light smoking decreases the incidence of fentanyl induced cough. Anesthesia and Analgesia 2005;101:670-4.

17. Oshima $T$, Kasuya $\mathrm{Y}$, Okumura. Identification of independent risk factors for fentanyl induced cough. Can J Anaesth 2006;53:753-8.

18. Jung HJ, Kim JB, Im KS. Effects of a priming dose of fentanyl during anaesthesia on the incidence and severity of fentanyl induced cough in current,former and non smokers. Journal of international medical research 2011;39:2379-2384.

19. Yasuda I, Hirano T, Yusa T. Tracheal constriction by morphine and by fentanyl in man. Anesthesiology 1978;49:117-9.

20. Weinger MB, Chen DY, Lin T. A role for CNS alpha -2 adrenergic receptors in opioid induced muscle rigidity in the rat. Brain Res 1995;669:10-18.

21. Hung KC. The possible mechanism of clonidine to suppress fentanyl induced coughing. Acta Anaesthesiol Scand 2009;53:1227-8.

22. Tang Q, Qian $Y$, Zhang Q. Effects of different priming doses of propofol on fentanyl induced cough during anesthesia induction: A preliminary randomized controlled study. Ups J Med Sci 2010;115:121-4.

23. Schlimp CJ, Wiedermann FJ. Does fentanyl induced cough justify pre treatment with IV lidocaaine 2 mg/kg. Can J Anaesth 2005;52:207. 